\title{
Free Vibrations of Beam System Structures with Elastic Boundary Conditions and an Internal Elastic Hinge
}

\author{
Alejandro R. Ratazzi, ${ }^{1}$ Diana V. Bambill,, ${ }^{1,2}$ and Carlos A. Rossit ${ }^{1,2}$ \\ ${ }^{1}$ Departamento de Ingeniería, Instituto de Mecánica Aplicada, (IMA), Universidad Nacional del Sur, (UNS), \\ 8000FTN Bahía Blanca, Argentina \\ ${ }^{2}$ Consejo Nacional de Investigaciones Científicas y Técnicas (CONICET), C1033AAJ Buenos Aires, Argentina \\ Correspondence should be addressed to Diana V. Bambill; dbambill@criba.edu.ar
}

Received 31 August 2013; Accepted 23 September 2013

Academic Editors: M. Chen and I. Smith

\begin{abstract}
Copyright ( 2013 Alejandro R. Ratazzi et al. This is an open access article distributed under the Creative Commons Attribution License, which permits unrestricted use, distribution, and reproduction in any medium, provided the original work is properly cited.

The study of the dynamic properties of beam structures is extremely important for proper structural design. This present paper deals with the free in-plane vibrations of a system of two orthogonal beam members with an internal elastic hinge. The system is clamped at one end and is elastically connected at the other. Vibrations are analyzed for different boundary conditions at the elastically connected end, including classical conditions such as clamped, simply supported, and free. The beam system is assumed to behave according to the Bernoulli-Euler theory. The governing equations of motion of the structural system in free bending vibration are derived using Hamilton's principle. The exact expression for natural frequencies is obtained using the calculus of variations technique and the method of separation of variables. In the frequency analysis, special attention is paid to the influence of the flexibility and location of the elastic hinge. Results are very similar with those obtained using the finite element method, with values of particular cases of the model available in the literature, and with measurements in an experimental device.
\end{abstract}

\section{Introduction}

The study of the dynamic properties of beam systems is very important in structural design as they are the cornerstone for many resistant structures.

The issue is relevant virtually in all fields of engineering: structures composed of beams can resist by virtue of its geometry. Such structures can be found from large scale, such as bridges and buildings located in seismically active regions to microbeam systems used in modern electronic equipment which is subject to vibration environment.

As Laura and his coworkers pointed out [1], many excellent books and technical papers deal with vibrating beam systems, including [2-6].

Many researchers have analyzed the vibration of beam systems. Reference [1] dealt with the determination of the fundamental frequency of vibration of a frame elastically restrained against translation and rotation at the ends, carrying concentrated masses. Reference [7] proposed a hybrid analytical/numerical method to do dynamic analysis of planar serial-frame structures. Reference [8] presented an elastic- and rigid-combined beam element to determine the dynamic characteristics of a two-dimensional frame composed of any number of beam segments. In his paper, Mei [6] considered the vibration in multistory planar beam structures from the wave vibration standpoint. Reference [9] analyzed in-plane vibrations of portal frames with elastically restrained ends. An approximate solution is obtained by means of a variational method.

In the particular case of L-beam structures, early studies have been done by [10-12]. In 2003, [13] extended the previous papers [12] by relaxing the restrictions on the motion of the open frame. In 2005, [14] determined natural frequencies and mode shapes of elastically restrained L-beams. They applied the separation of variables method for the determination of the exact eigenfrequencies and mode shapes and calculated the eigenvalues numerically by applying the Newton method strategy to the corresponding frequency equation. Reference [15] used a formulation by the RayleighRitz method together with the introduction of artificial linear and torsional springs for computing the natural frequencies 
and modes for the in-plane vibrations of complex planar beam structures.

The presence of an internal hinge in beams has been treated in several papers including [16-22]. Here, we deal with the vibration of L-beams structures assuming an internal hinge in different positions of the structural system.

The two parts of the L-shaped geometry are joined at right angle, with the end of one of them clamped and the end of the other elastically restrained. Figure 1 depicts the structure under study.

Classical structural models do not consider the properties of the connection stiffness, because they are based only on models with pinned or rigid joints. Many authors have studied structures with flexibly connected members as it is known that the behavior of the connection plays an important role in analysis and design. Reference [23] presented a computerbased method for geometrically nonlinear beam system with semirigid beam-to-column connections. Reference [24] studied wooden framed structures; they considered that mechanical connections are recognized as extremely important elements in the aspect of strength and structural safety. Reference [25] studied steel frames and observed that the interstory shears generally increase when the connections stiffness is taken into account. As known, ideal supports used in many structural models do not fit exactly real supports.

In the current presentation it is assumed that the beams are adequately modeled using Euler-Bernoulli theory, so that the effects of shear deformation and rotatory inertia are considered to be small, and they are neglected in the analysis. The cross sections of beam elements have double symmetry (the shear centre and centroid are coincident), so it can be assumed that there is no coupling between bending displacements and torsional rotations.

The beam system is modeled in Mathematica code [26] using the method of separation of variables to obtain the exact values of the natural frequency coefficients.

Finally, numerical results are shown for slender beam systems by considering the effects of different stiffness of the elastic connections. A comparison is made with results obtained by the authors with the finite element method, [27] and with values available in the literature. In addition, some particular cases are also compared with the experimental results of a specially constructed device.

\section{Theory}

A more realistic model of an L-geometry beam system is presented to analyze the natural vibration problem. The structure under study has elastic restrains at $\mathrm{F}$ and a clamped end $\mathrm{H}$ as it is shown in Figure 1, with $\left(\alpha_{1}+\alpha_{3}=\pi / 2\right)$. It is assumed that the elastic internal hinge at $\mathrm{P}$ can be located in different positions. The structure has three beam members: FO beam, with length $l_{1}$; OP beam, with length $l_{2}$; and $\mathrm{PH}$ beam, with length $l_{3}$. Each of them has uniform properties throughout its length. The influence of the type of connection between beamelements of the structural system and elastic conditions on the outer edge $\mathrm{F}$ is considered in the study. The external end $\mathrm{H}$ has a classical clamped condition, while the external end $\mathrm{F}$ is supported by two translational springs of stiffness $t_{w}$ and $t_{u}$

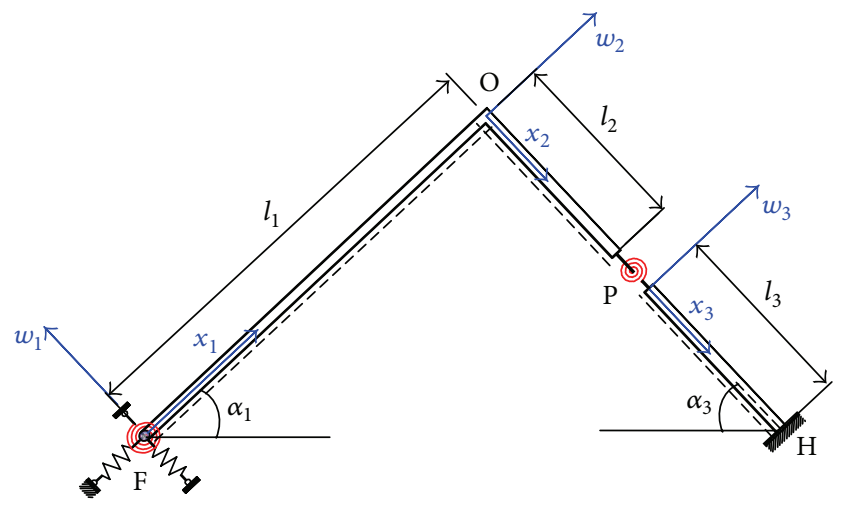

Figure 1: Beam system structure.

and a rotational spring of stiffness $r_{z}$, Figure 2(a). At point $\mathrm{P}$, there is an internal hinge, elastically restrained against rotation between beams 2 , OP, and $3, \mathrm{PH}$; this semirigid connection is materialized by a rotational spring of stiffness $r_{m}$, Figure 2(b).

The flexural rigidity, the mass density, the length, and the area of the cross section of each beam are $E_{i} I_{i}, \rho_{i}, l_{i}$, and $A_{i}$, with $i=1,2,3$.

Three coordinate systems are located as shown in Figure 1. Respectively, each coordinate origin is at the point F, O, or $\mathrm{P}$. At abscissa $x_{i}\left(0 \leq x_{i} \leq l_{i}\right)$ and at any time $t: w_{i}$ is the flexural displacement in the transverse direction of the beam's neutral axis, $\theta_{i}=\partial w_{i} / \partial x_{i}$ is the section rotation, and $u_{i}$ is the axial displacement. The deformation of a beam in the $x$ direction is not taken into account. The beams are considered infinitely rigid in the $x$ direction.

The sign convention used for the positive shear force spins an element clockwise (up on the left and down on the right). Likewise the normal convention for a positive bending moment elongates the reference fiber of the beam indicated by the dotted line. Figure 3 shows the sign convention to be employed.

For free vibration, the bending moment and the shear force expressions are

$$
\begin{aligned}
& Q_{i}\left(x_{i}, t\right)=\left.E_{i} I_{i} \frac{\partial^{3} w_{i}}{\partial x_{i}^{3}}\right|_{\left(x_{i}, t\right)}, \\
& M_{i}\left(x_{i}, t\right)=\left.E_{i} I_{i} \frac{\partial^{2} w_{i}}{\partial x_{i}^{2}}\right|_{\left(x_{i}, t\right)} .
\end{aligned}
$$

At time $t$, the kinetic energy of the beams is given by

$$
\begin{aligned}
T^{*}= & \sum_{i=1}^{3} \frac{1}{2}\left(\int_{0}^{l_{i}} \rho_{i} A_{i}\left(\left.\frac{\partial w_{i}}{\partial t}\right|_{\left(x_{i}, t\right)}\right)^{2} d x_{i}\right) \\
& +\frac{\rho_{1} A_{1} l_{1}}{2}\left(\left.\frac{\partial u_{1}}{\partial t}\right|_{\left(l_{1}, t\right)}\right)^{2} .
\end{aligned}
$$

The last term of the kinetic energy expression is due to the rigid body translation of beam 1 of length $l_{1}$. Due to the assumption of infinity axial rigidity, $\partial u_{1} / \partial t$ at $x_{1}=l_{1}$ is equal to $\partial w_{2} / \partial t$ at $x_{2}=0$; therefore in (2) the expression $\left.\left(\partial u_{1} / \partial t\right)^{2}\right|_{\left(l_{1}, t\right)}$ can also be replaced by $\left.\left(\partial w_{2} / \partial t\right)^{2}\right|_{(0, t)}$. 


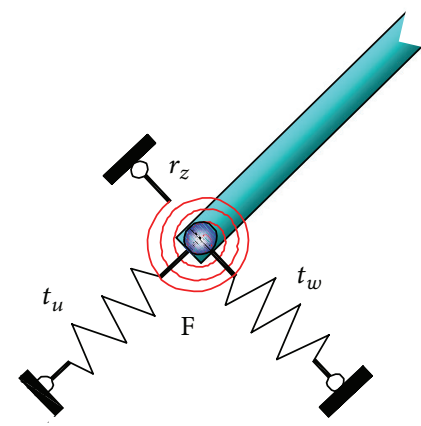

(a)

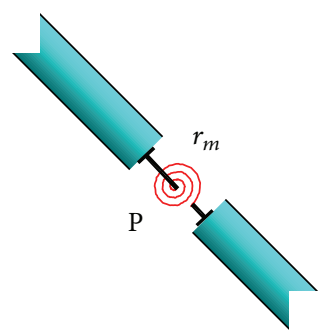

(b)

FIgURE 2: (a) Elastic boundary conditions at end F; (b) elastic internal hinge at joint P.

On the other hand, the potential energy of the mechanical system is given by

$$
\begin{aligned}
U^{*}= & \frac{1}{2} \sum_{i=1}^{3}\left[\int_{0}^{l_{i}} E_{i} I_{i}\left(\left.\frac{\partial^{2} w_{i}}{\partial x_{i}^{2}}\right|_{\left(x_{i}, t\right)}\right)^{2} d x_{i}\right] \\
& +\frac{1}{2} r_{m}\left(\left.\frac{\partial w_{2}}{\partial x_{2}}\right|_{\left(l_{2}, t\right)}-\left.\frac{\partial w_{3}}{\partial x_{3}}\right|_{(0, t)}\right)^{2} \\
& +\frac{1}{2} r_{z}\left(\left.\frac{\partial w_{1}}{\partial x_{1}}\right|_{(0, t)}\right)^{2}+\frac{1}{2} t_{w}\left(w_{1}(0, t)\right)^{2} \\
& +\frac{1}{2} t_{u}\left(u_{1}(0, t)\right)^{2},
\end{aligned}
$$

which involves the work of the elastic constrains. And again due to the assumption of infinity axial stiffness, $u_{1}(0, t)=$ $u_{1}\left(l_{1}, t\right)=w_{2}(0, t)$; therefore in $(3)$ the expression $\left(u_{1}(0, t)\right)^{2}$ can also be replaced by $\left(w_{2}(0, t)\right)^{2}$.

To express equations in dimensionless form, the nondimensional parameter is introduced:

$$
X_{i}=\frac{x_{i}}{l_{i}}, \quad \text { with } X_{i} \in[0,1] \forall i=1,2,3 .
$$

The displacements $u_{i}$ and $w_{i}$, and $\theta_{i}$ may be expressed in terms of the dimensionless coordinates as follows:

$$
\begin{gathered}
W_{i}\left(X_{i}, t\right)=\frac{w_{i}\left(x_{i}, t\right)}{l_{i}}, \\
\theta_{i}\left(X_{i}, t\right)=\left.\frac{\partial W_{i}}{\partial X_{i}}\right|_{\left(X_{i}, t\right)}=\left.\frac{\partial w_{i}}{\partial x_{i}}\right|_{\left(x_{i}, t\right)}, \\
U_{i}\left(X_{i}, t\right)=\frac{u_{i}\left(x_{i}, t\right)}{l_{i}} .
\end{gathered}
$$

The characteristics of beam 1 are used as "reference":

$$
E I=E_{1} I_{1}, \quad \rho A=\rho_{1} A_{1}, \quad l=l_{1},
$$

to define the ratios:

$$
v_{E I_{i}}=\frac{E_{i} I_{i}}{E I}, \quad v_{\rho A_{i}}=\frac{\rho_{i} A_{i}}{\rho A}, \quad v_{l_{i}}=\frac{l_{i}}{l},
$$

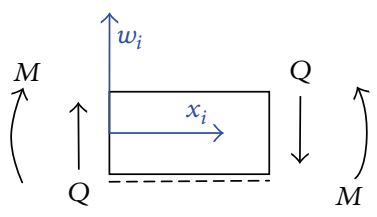

FIGURE 3: Sign convention for positive transverse displacement $(w)$, shear force $(Q)$, and bending moment $(M)$.

the dimensionless spring stiffness:

$$
\begin{array}{rlrl}
T_{w} & =t_{w} \frac{l^{3}}{E I}, & T_{u}=t_{u} \frac{l^{3}}{E I}, \\
R_{z}=r_{z} \frac{l}{E I}, & R_{m}=r_{m} \frac{l}{E I},
\end{array}
$$

and the dimensionless frequency coefficient:

$$
\lambda^{4}=l^{4} \omega^{2} \frac{\rho A}{E I},
$$

where $\omega$ is the circular natural frequency of the vibrating system in radians per second.

The expression of the energy functional of the system of beams is $J=T^{*}-U^{*}$.

Hamilton's principle requires that $\delta \int_{t_{a}}^{t_{b}} J d t$ taken between arbitrary intervals of time $\left(t_{a}, t_{b}\right)$ at which the positions of the mechanical system are known is equal to zero. That means that the system should execute a motion which makes the functional $J$ stationary on the space of admissible functions:

$$
\begin{array}{r}
\delta \int_{t_{a}}^{t_{b}}\left(T^{*}-U^{*}\right) d t=0, \\
\delta \int_{t_{a}}^{t_{b}}\left(T^{*}-U^{*}\right) d t
\end{array}
$$

$$
=\delta\left\{\frac{1}{2} \rho A l^{3}\right.
$$

$$
\times\left\{\int _ { t _ { a } } ^ { t _ { b } } \left[\sum_{i=1}^{3} \int_{0}^{1} v_{\rho A_{i}} v_{l_{i}}^{3}\left(\left.\frac{\partial W_{i}}{\partial t}\right|_{\left(X_{i}, t\right)}\right)^{2} d X_{i}\right.\right.
$$




$$
\begin{gathered}
\left.\left.+v_{\rho A_{1}} v_{l_{1}} v_{l_{2}}^{2}\left(\left.\frac{\partial W_{2}}{\partial t}\right|_{(0, t)}\right)^{2}\right] d t\right\} \\
-\frac{1}{2} \frac{E I}{l}\left\{\int_{t_{a}}^{t_{b}}\left[\sum_{i=1}^{3} \int_{0}^{1} \frac{v_{E I_{i}}}{v_{l_{i}}}\left(\left.\frac{\partial^{2} W_{i}}{\partial X_{i}^{2}}\right|_{\left(X_{i}, t\right)}\right)^{2} d X_{i}\right] d t\right. \\
+\int_{t_{a}}^{t_{b}} R_{m}\left(\left.\frac{\partial W_{2}}{\partial X_{2}}\right|_{(1, t)}-\left.\frac{\partial W_{3}}{\partial X_{3}}\right|_{(0, t)}\right)^{2} d t \\
+\int_{t_{a}}^{t_{b}} R_{z}\left(\left.\frac{\partial W_{1}}{\partial X_{1}}\right|_{(0, t)}\right)^{2} d t \\
+\int_{t_{a}}^{t_{b}} T_{w}\left(v_{l_{1}}\right)^{2}\left(W_{1}(0, t)\right)^{2} d t \\
\left.\left.+\int_{t_{a}}^{t_{b}} T_{u}\left(v_{l_{2}}\right)^{2}\left(W_{2}(0, t)\right)^{2} d t\right\}\right\} .
\end{gathered}
$$

Taking into account the boundary conditions at the ends, the compatibility, and equilibrium conditions at the joints between beam elements and applying the procedure of calculus of variations in (10), the following boundary and eigenvalue problem is obtained

$$
\begin{aligned}
& \left.\frac{\partial^{4} W_{1}}{\partial X_{1}^{4}}\right|_{\left(X_{1}, t\right)}+\left.k_{1}^{4} \frac{\partial^{2} W_{1}}{\partial t^{2}}\right|_{\left(X_{1}, t\right)}=0, \\
& \left.\frac{\partial^{4} W_{2}}{\partial X_{2}^{4}}\right|_{\left(X_{2}, t\right)}+\left.k_{2}^{4} \frac{\partial^{2} W_{2}}{\partial t^{2}}\right|_{\left(X_{2}, t\right)}=0, \\
& \left.\frac{\partial^{4} W_{3}}{\partial X_{3}^{4}}\right|_{\left(X_{3}, t\right)}+\left.k_{3}^{4} \frac{\partial^{2} W_{3}}{\partial t^{2}}\right|_{\left(X_{3}, t\right)}=0,
\end{aligned}
$$

with $k_{i}^{4}=\left(\rho_{i} A_{i} / E_{i} I_{i}\right) l_{i}^{4}, i=1,2,3$.

Consider

$$
\begin{aligned}
& v_{l_{1}} W_{1}(1, t)=0, \quad v_{l_{2}} W_{2}(1, t)=v_{l_{3}} W_{3}(0, t), \\
& \left.\frac{\partial W_{1}}{\partial X_{1}}\right|_{(1, t)}=\left.\frac{\partial W_{2}}{\partial X_{2}}\right|_{(0, t)}, \\
& \left.\frac{v_{E I_{1}}}{v_{l_{1}}} \frac{\partial^{2} W_{1}}{\partial X_{1}^{2}}\right|_{(1, t)}=\left.\frac{v_{E I_{2}}}{v_{l_{2}}} \frac{\partial^{2} W_{2}}{\partial X_{2}^{2}}\right|_{(0, t)} \text {, } \\
& \left.\frac{v_{E I_{2}}}{v_{l_{2}}} \frac{\partial^{2} W_{2}}{\partial X_{2}^{2}}\right|_{(1, t)}-R_{m}\left(\left.\frac{\partial W_{3}}{\partial X_{3}}\right|_{(0, t)}-\left.\frac{\partial W_{2}}{\partial X_{2}}\right|_{(1, t)}\right)=0 \text {, } \\
& \left.\frac{v_{E I_{3}}}{v_{l_{3}}} \frac{\partial^{2} W_{3}}{\partial X_{3}^{2}}\right|_{(0, t)}-R_{m}\left(\left.\frac{\partial W_{3}}{\partial X_{3}}\right|_{(0, t)}-\left.\frac{\partial W_{2}}{\partial X_{2}}\right|_{(1, t)}\right)=0 \text {, } \\
& \left.\frac{v_{E I_{1}}}{\left(v_{l_{1}}\right)^{2}} \frac{\partial^{3} W_{1}}{\partial X_{1}^{3}}\right|_{(0, t)}+T_{w} v_{l_{1}} W_{1}(0, t)=0,
\end{aligned}
$$

$$
\begin{gathered}
\left.\frac{v_{E I_{2}}}{v_{l_{2}}^{2}} \frac{\partial^{3} W_{2}}{\partial X_{2}^{3}}\right|_{(1, t)}-\left.\frac{v_{E I_{3}}}{v_{l_{3}}^{2}} \frac{\partial^{3} W_{3}}{\partial X_{3}^{3}}\right|_{(0, t)}=0, \\
\left.\frac{v_{E I_{2}}}{\left(v_{l_{2}}\right)^{2}} \frac{\partial^{3} W_{2}}{\partial X_{2}^{3}}\right|_{(0, t)}+T_{u} v_{l_{2}} W_{2}(0, t) \\
-k^{4} v_{l_{1}} v_{l_{2}} W_{2}(0, t)=0, \\
\left.\frac{v_{E I_{1}}}{v_{l_{1}}} \frac{\partial^{2} W_{1}}{\partial X_{1}^{2}}\right|_{(0, t)}-\left.R_{z} \frac{\partial W_{1}}{\partial X_{1}}\right|_{(0, t)}=0, \\
v_{l_{3}} W_{3}(1, t)=0,\left.\quad \frac{\partial W_{3}}{\partial X_{3}}\right|_{(1, t)}=0 .
\end{gathered}
$$

Using the well-known separation of variables method, solution of (12) is assumed to be of the form:

$$
\begin{gathered}
W_{1}\left(X_{1}, t\right)=\sum_{n=1}^{\infty} W_{1 n}\left(X_{1}\right) T(t), \\
W_{2}\left(X_{2}, t\right)=\sum_{n=1}^{\infty} W_{2 n}\left(X_{2}\right) T(t), \\
W_{3}\left(X_{3}, t\right)=\sum_{n=1}^{\infty} W_{3 n}\left(X_{3}\right) T(t) .
\end{gathered}
$$

The functions $W_{1 n}, W_{2 n}$, and $W_{3 n}$ represent the corresponding transverse modes of natural vibration of each beam member and are given by

$$
\begin{aligned}
W_{1 n}\left(X_{1}\right)= & C_{1} \cosh \left(\lambda_{n} \alpha_{1} X_{1}\right)+C_{2} \operatorname{senh}\left(\lambda_{n} \alpha_{1} X_{1}\right) \\
& +C_{3} \cos \left(\lambda_{n} \alpha_{1} X_{1}\right)+C_{4} \operatorname{sen}\left(\lambda_{n} \alpha_{1} X_{1}\right), \\
W_{2 n}\left(X_{2}\right)= & C_{5} \cosh \left(\lambda_{n} \alpha_{2} X_{2}\right)+C_{6} \operatorname{senh}\left(\lambda_{n} \alpha_{2} X_{2}\right) \\
& +C_{7} \cos \left(\lambda_{n} \alpha_{2} X_{2}\right)+C_{8} \operatorname{sen}\left(\lambda_{n} \alpha_{2} X_{2}\right), \\
W_{3 n}\left(X_{3}\right)= & C_{9} \cosh \left(\lambda_{n} \alpha_{3} X_{3}\right)+C_{10} \operatorname{senh}\left(\lambda_{n} \alpha_{3} X_{3}\right) \\
& +C_{11} \cos \left(\lambda_{n} \alpha_{3} X_{3}\right)+C_{12} \operatorname{sen}\left(\lambda_{n} \alpha_{3} X_{3}\right),
\end{aligned}
$$

where $\alpha_{i}=v_{l_{i}} \sqrt[4]{v_{\rho A_{i}} / v_{E I_{i}}}$ is a mechanical and geometrical parameter, with $i=1,2,3, \lambda_{n}=\sqrt[4]{l^{4} \omega_{n}^{2} \rho A /(E I)}$ is the dimensionless frequency coefficient of mode of vibration $n$, and $C_{1}, C_{2}, \ldots, C_{12}$ are arbitrary constants to be determined.

Replacing expressions (15) in (14) and these ones in (13), a linear system of equations in the unknown constants $C_{1}$, $C_{2}, \ldots, C_{12}$ is obtained.

For a nontrivial solution to exist the determinant of the coefficient matrix in the linear system of equations should be equal to zero and the roots of the transcendental frequency equation are the dimensionless frequency coefficients of the mechanical system in Figure 1.

\section{Finite Element Method}

The authors solved some numerical examples using the finite element method, using the software ALGOR 23.1 [27]. 


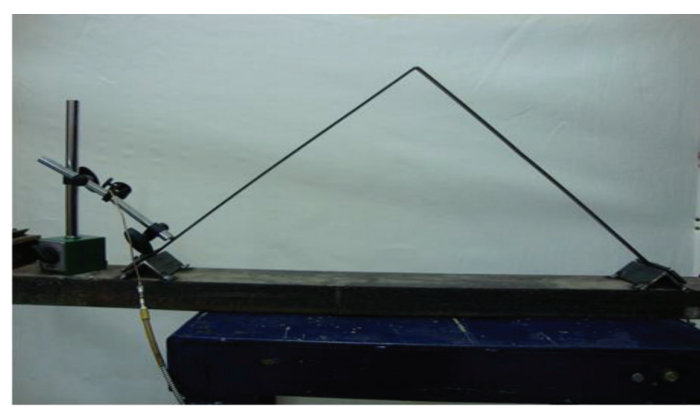

Figure 4: Experimental system device; C-C model.

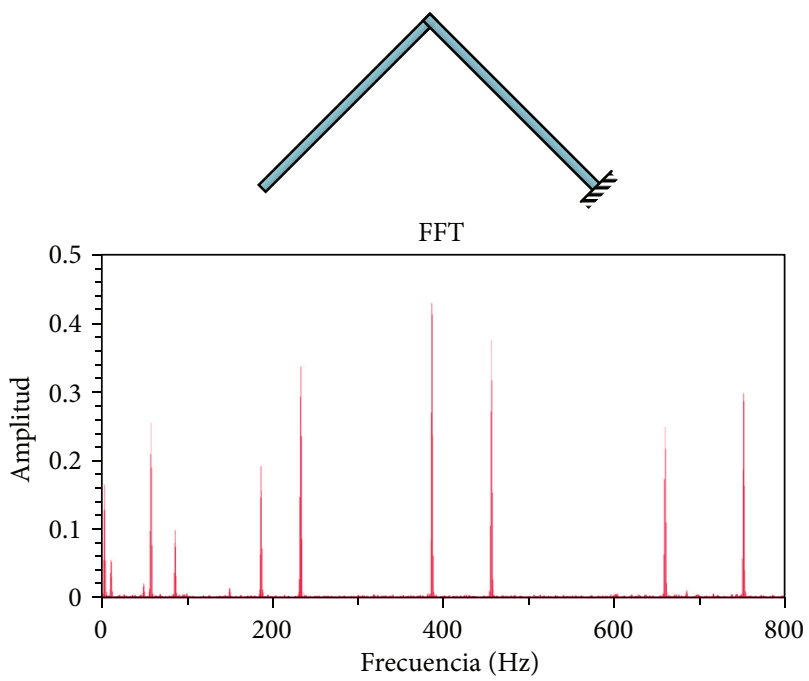

FIGURE 5: Spectrum of the first natural frequency; Case a: F-C model.

The three members of the structure are divided into 100 beams elements, respectively, each beam element with three degrees of freedom.

The internal hinge elastically restrained was modeled by a very small beam element, 300 times smaller than the length of the beam. The moment of inertia of the section was varied in order to obtain stiffness values that are equivalent to the stiffness constants of the spring connecting the two sections at location P.

\section{Experimental Model}

An experimental model was built of steel to compare the results obtained by the analytical and finite element models.

The experimental beam system has two parts of equal length $l$ (see Figure 4). It was tested under two different boundary conditions (clamped and free at $x_{1}=0$ ) while the other end $\left(x_{3}=1\right)$ was clamped. The presence of an internal hinge was not considered. The geometry of the structural system is described by $l=l_{1}=l_{2}+l_{3}=0.50 \mathrm{~m} ; A=A_{i}=4.064 \times$ $10^{-5} \mathrm{~m}^{2} ; I=I_{i}=3.468 \times 10^{-11} \mathrm{~m}^{4} ;$ and the material properties are $\rho=\rho_{i}=7870 \mathrm{~kg} / \mathrm{m}^{3}$ and $E=E_{i}=2.1 \times 10^{6} \mathrm{~kg} / \mathrm{cm}^{2}$, with $i=1,2,3$.

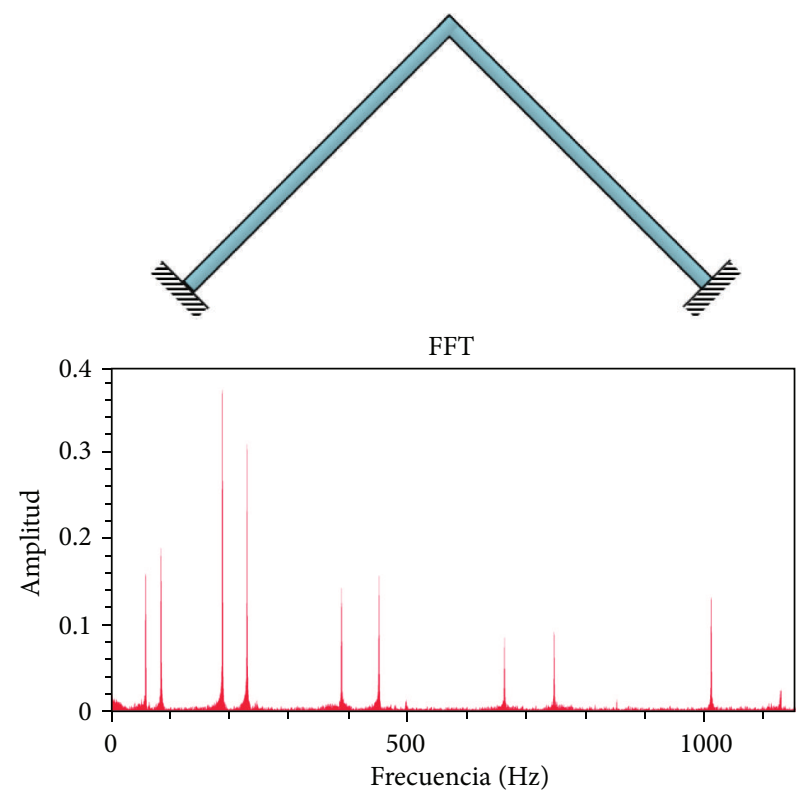

Figure 6: Spectrum of the first natural frequency; Case b: C-C model.

In order to measure the natural frequencies, an optical proximity sensor was used as it is seen in Figure 4.

Figures 5 and 6 show the spectrum of the first ten natural frequencies of the free-clamped (Case a) and the clampedclamped (Case $\mathrm{b}$ ) beam systems, respectively.

\section{Numerical Results}

Frequency coefficients were obtained by the exact analytical solution, with the finite element method, FEM, [27] and with the experimental model.

Table 1 presents the first ten coefficients of natural frequency of vibration of a beam structure with free-clamped boundary conditions without internal hinge, Figure 5.

For the analytical solution the parameters are taken as

$$
\begin{gathered}
v_{\rho A_{i}}=1, \quad v_{E I_{i}}=1, \quad \forall i=1,2,3, \\
v_{l_{1}}=2 v_{l_{2}}=2 v_{l_{3}}=1 .
\end{gathered}
$$

The analytical solution for Case a: F-C model, was obtained with $T_{u}=T_{w}=R_{z}=0 ; R_{m} \rightarrow \infty$. It is remarkable that for the first ten frequencies, the analytical results are very close to the experimental ones. The analytical results are also compared with previous published ones, [7]. As it can be seen in the table all of them are in excellent agreement.

The exact analytical solution for C-C structure was obtained with $T_{u}=T_{w}=R_{z}=R_{m} \rightarrow \infty$.

Table 2 shows the first ten coefficients of natural frequency of vibration of the beam structure with clampedclamped boundary conditions. Again the first ten frequency coefficients obtained by the analytical model are very similar to the experimental model. They also are in excellent agreement with the FEM solution and previous published results [14]. 
Table 3 shows the frequency coefficients for pinnedclamped L-beams obtained by the analytical procedure and the finite element method. For the analytical solution the spring constants are assigned in two different ways to model the simply supported-clamped system:

(1) $v_{E I_{i}}=1, v_{\rho A_{i}}=1$, for all $i=1,2,3, v_{l_{2}}=v_{l_{3}}=1 / 2$, $T_{w} \rightarrow \infty, T_{u} \rightarrow \infty, R_{z}=0$, and $R_{m} \rightarrow \infty$.

(2) $v_{E I_{i}}=1, v_{\rho A_{i}}=1$, for all $i=1,2,3, v_{l_{2}}=0.99, v_{l_{3}}=$ $0.01, T_{w} \rightarrow \infty, T_{u} \rightarrow \infty, R_{z} \rightarrow \infty$, and $R_{m}=0$.

The percentage differences between both sets of results are shown in file $|\Delta| \%$. Although both sets of results correspond to a simply supported-clamped system, the small percentage differences, less than $0.7 \%$, are due to the different numerical computational aspects between the analytical models (1) and (2). The results were determined using the Mathematica software [26] with five significant figures.

Table 4 compares the first five natural coefficients of vibration for a free-clamped system with Morales published results [28]. The characteristics of Morales frame are $l_{1}=$ $2.215 \mathrm{~m}$ and $l_{2}+l_{3}=4.249 \mathrm{~m}, E_{1} I_{1}=0.0147 \mathrm{Nm}^{2}, E_{2} I_{2}=$ $E_{3} I_{3}=0.0267 \mathrm{Nm}^{2}, m_{1}=6 \times 10^{-3} \mathrm{~kg} / \mathrm{m}$, and $m_{2}=m_{3}=$ $4.5 \times 10^{-5} \mathrm{~kg} / \mathrm{m}$. For the analytical solution, the parameters are assumed as $l_{1}=2.215 \mathrm{~m}, l_{2}=2.249 \mathrm{~m}, l_{3}=2.000 \mathrm{~m}$, $v_{l_{1}}=1, v_{E I_{1}}=1, v_{\rho A_{1}}=1, v_{l_{2}}=1.0153, v_{E I_{2}}=1.8163, v_{\rho A_{2}}=$ $0.0075, v_{l_{3}}=0.0903, v_{E I_{3}}=1.8163, v_{\rho A_{3}}=0.0075, T_{w}=0$, $R_{z}=0, \stackrel{3}{T}_{u}=0$, and $R_{m} \rightarrow \infty$. It can be verified that our results are in excellent agreement whit those obtained by Morales.

Traditionally, the analysis and design of beam structures have been based on the assumption that the boundary conditions are rigid. The disadvantage of this model is that the flexibility of the real boundary conditions is neglected and therefore the real natural frequencies cannot be obtained.

Thus, we now analyze the case of beam system structure with elastic boundary conditions at edge $\mathrm{F}$ and clamped at the other end $\mathrm{H}$, while the internal elastic hinge (at section $\mathrm{P}$ ) is assumed to have $R_{m} \rightarrow \infty$. Numerical simulations are carried out to investigate the effect of the rigidity of the boundary conditions on the natural frequencies of the system.

In Figure 7 the effect of rigidity $T_{u}$ of the translational spring on the frequency coefficients of the structure is shown. It can be seen that the first frequency coefficient $\lambda_{1}$ increases with increasing the value of $T_{u}$, from $T_{u}=0, \lambda_{1}=1.5208$ to $T_{u} \rightarrow 200, \lambda_{1}=3.3762$. For values larger than 200 the fundamental coefficient stays practically the same: $T_{u} \rightarrow \infty$, $\lambda_{1}=3.3920$. Its increase is of $124 \%$.

The second frequency is 3.3947 for $T_{u}=0$ and 4.4566 for $T_{u} \rightarrow \infty$; its increase is of $31 \%$ and the most significant change occurs between $T_{u}=200$ and $T_{u}=1000$. The higher frequency coefficients exhibit a similar behavior.

From Figure 7 it could be concluded that the first and second frequencies interchange their modal shape for a value of $T_{u}$ between 100 and 1000. A similar behaviour occurs in the case of third and fourth frequencies for a value of $T_{u}$ between 1000 and 10000.

Figure 8 shows the effect of $T_{w}$ on the first natural frequency coefficients. Again it is observed as a matter of course that the natural frequency coefficients increase with the spring constant parameter.

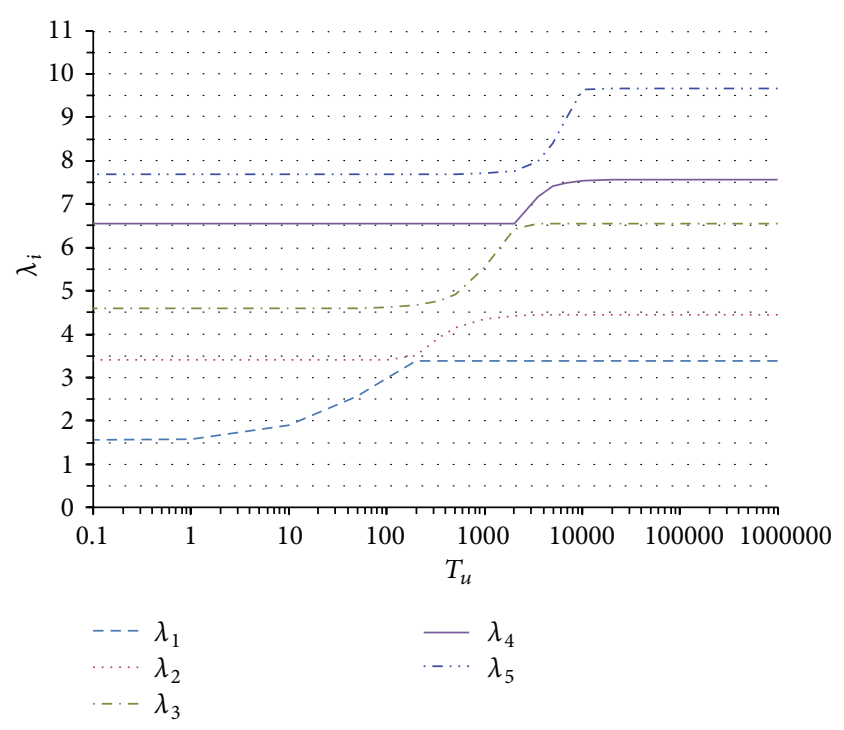

FIGURE 7: Effect of $T_{u}$ on the first five natural frequency coefficients. $l_{2}=l_{3}, v_{l_{1}}=v_{l_{2}}=0.5, v_{E I_{(2)}}=v_{E I_{(3)}}=1, v_{\rho A_{(2)}}=v_{\rho A_{(3)}}=1$, $R_{m} \rightarrow \infty, R_{z}=0$, and $T_{w} \rightarrow \infty$.

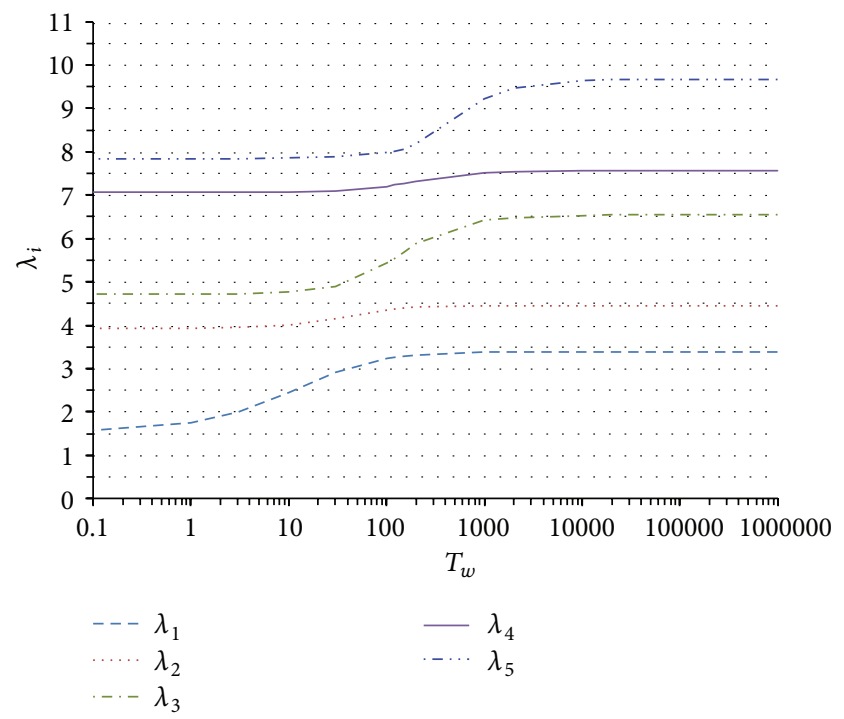

FIGURE 8: Effect of $T_{w}$ on the first five natural frequency coefficients. $l_{2}=l_{3}, v_{l_{1}}=v_{l_{2}}=0.5, v_{E I_{(2)}}=v_{E I_{(3)}}=1, v_{\rho A_{(2)}}=v_{\rho A_{(3)}}=1$, $R_{m} \rightarrow \infty, R_{z}=0$, and $T_{u} \rightarrow \infty$.

Figure 9 shows that the effect of the spring $R_{z}$ is small.

Table 5 presents the case of a clamped-clamped structure with an elastic joint at $l_{2}=0.5 l_{1}$, and $R_{m}$ is the constant rigidity of the rotational spring at $\mathrm{P}$ that connects the beam members indicated as OP and PH. In this table $R_{m}$ assumes different values from infinity to zero. It can be seen that all the first frequency coefficients decrease in value, except for $\lambda_{4}$, which practically remains constant.

Table 6 presents the case of a clamped-clamped structure with an elastic connection at $\mathrm{P}, l_{2} \rightarrow 0, l_{3}=l_{1}$. In this table, $R_{m}$ assumes different values, from $\rightarrow \infty$ to 0 . It can 
TABLE 1: Comparison of the first ten frequency coefficients $\lambda_{n}=\sqrt[4]{l^{4} \omega_{n}^{2}(\rho A / E I)}$ for L-beams: Case a: F-C.

\begin{tabular}{lcccccccccc}
\hline$\lambda_{1}$ & $\lambda_{2}$ & $\lambda_{3}$ & $\lambda_{4}$ & $\lambda_{5}$ & $\lambda_{6}$ & $\lambda_{7}$ & $\lambda_{8}$ & $\lambda_{9}$ & $\lambda_{10}$ & \\
\hline$f_{1}=4.30$ & 11.90 & 58.59 & 86.67 & 185.38 & 233.76 & 386.96 & 456.54 & 659.79 & 751.3 & ${ }^{*}$ Experimental, in hertz \\
\hline 1.0811 & 1.7985 & 3.9907 & 4.8537 & 7.0986 & 7.9541 & 10.255 & 11.139 & 13.392 & 14.290 & ${ }^{* *}$ Experimental, adimensional \\
1.0820 & 1.7863 & 3.9680 & 4.8031 & 7.0981 & 7.9131 & 10.229 & 11.034 & 13.368 & 14.171 & Exact analytical solution \\
1.0854 & 1.7903 & 3.9753 & 4.8077 & 7.0956 & 7.9307 & 10.225 & 11.059 & 13.355 & 14.191 & FEM \\
1.0880 & 1.7869 & 3.9685 & 4.8021 & 7.0915 & - & - & - & - & - & Lin and Ro, 2003 [7] \\
\hline
\end{tabular}

${ }^{*}$ Experimental, in hertz: values $f_{n}$ were measured in the experimental model (Figure 5).

** Experimental, adimensional: values were obtained from $f_{n}$ measured values: $\lambda_{n}=l \cdot \sqrt[4]{\left(2 \pi f_{n}\right)^{2}(\rho A / E I)}$.

TABLE 2: Comparison of the first ten frequency coefficients $\lambda_{n}=\sqrt[4]{l^{4} \omega_{n}^{2}(\rho A / E I)}$ for L-beams: Case b: C-C.

\begin{tabular}{lcccccccccc}
\hline$\lambda_{1}$ & $\lambda_{2}$ & $\lambda_{3}$ & $\lambda_{4}$ & $\lambda_{5}$ & $\lambda_{6}$ & $\lambda_{7}$ & $\lambda_{8}$ & $\lambda_{9}$ & $\lambda_{10}$ & \\
\hline$f_{1}=56.76$ & 82.01 & 182.5 & 225.88 & 382.08 & 448.0 & 653.08 & 737.92 & 992.43 & 1105.3 & ${ }^{*}$ Experimental, in hertz \\
\hline 3.9270 & 4.7214 & 7.0432 & 7.8357 & 10.190 & 11.035 & 13.323 & 14.162 & 16.424 & 17.333 & ${ }^{* *}$ Experimental, adimensional \\
3.9229 & 4.7227 & 7.0528 & 7.8249 & 10.159 & 10.838 & 13.310 & 14.137 & 16.345 & 17.178 & Exact analytical solution \\
3.9319 & 4.7295 & 7.0613 & 7.8187 & 10.158 & 11.014 & 13.337 & 14.152 & 16.465 & 17.282 & FEM \\
3.9222 & 4.7142 & 7.0376 & 7.7588 & 10.007 & - & - & - & - & - & Albarracín and Grossi, 2005 [14] \\
\hline
\end{tabular}

${ }^{*}$ Experimental, in hertz: values $f_{n}$ were measured in the experimental model (Figure 6).

** Experimental, adimensional: values were obtained from $f_{n}$ measured values: $\lambda_{n}=l \cdot \sqrt[4]{\left(2 \pi f_{n}\right)^{2}(\rho A / E I)}$.

TABLE 3: Frequency coefficients $\lambda_{n}=\sqrt[4]{l^{4} \omega_{n}^{2}(\rho A / E I)}$ for simply supported-clamped beam system; comparison of results.

\begin{tabular}{lccccc}
\hline$\lambda_{1}$ & $\lambda_{2}$ & $\lambda_{3}$ & $\lambda_{4}$ & $\lambda_{5}$ & \\
\hline 3.3920 & 4.4566 & 6.5383 & 7.5702 & 9.6637 & Exact analytical solution $(1)$ \\
3.3943 & 4.4266 & 6.5798 & 7.5666 & 9.6584 & Exact analytical solution $(2)$ \\
$0.07 \%$ & $0.68 \%$ & $0.63 \%$ & $0.05 \%$ & $0.05 \%$ & $|\Delta|=((1)-(2)) /(2) \%($ difference $)$ \\
3.3900 & 4.4266 & 6.5292 & 7.5608 & 9.6301 & FEM \\
\hline
\end{tabular}

TABLE 4: Non dimensional frequency coefficients $\lambda_{n}=\sqrt[4]{l^{4} \omega_{n}^{2}(\rho A / E I)}$ for free-clamped beam system; comparison of results.

\begin{tabular}{lccccc}
\hline$\lambda_{1}$ & $\lambda_{2}$ & $\lambda_{3}$ & $\lambda_{4}$ & $\lambda_{5}$ & \\
\hline 1.0301 & 1.9062 & 3.5186 & 5.1798 & 6.1299 & Exact analytical solution \\
1.0385 & 1.9198 & 3.5277 & 5.1787 & 6.1156 & FEM \\
\hline 1.0229 & 1.9229 & 3.5337 & 5.1844 & 6.1330 & (Morales, 2009 [28]) 12-DOF RRMSSM \\
1.0229 & 1.9229 & 3.5337 & 5.1844 & 6.1330 & (Morales, 2009 [28]) 60-DOF FEM \\
1.0229 & 1.9229 & 3.5337 & 5.1841 & 6.1329 & (Morales, 2009 [28]) Analytical \\
\hline
\end{tabular}

TABLE 5: Effect of $R_{m}$ on the first five non dimensional frequency coefficients of a C-C system, with an elastic joint at $l_{2}=0.5 l_{1}$, beam-beam connection.

\begin{tabular}{lcccccc}
\hline$R_{m}$ & $\lambda_{1}$ & $\lambda_{2}$ & $\lambda_{3}$ & $\lambda_{4}$ & $\lambda_{5}$ & Exact analytical solution \\
\hline$\rightarrow \infty$ & 3.9229 & 4.7227 & 7.0528 & 7.8248 & 10.1595 & 10.1595 \\
100 & 3.9229 & 4.7227 & 7.0528 & 7.8248 & 10.1327 & \\
50 & 3.9145 & 4.7121 & 7.0499 & 7.8248 & 10.1086 \\
20 & 3.9110 & 4.7082 & 7.0498 & 7.8248 & 7.0438 & \\
10 & 3.9818 & 4.6862 & 7.0436 & 7.8248 & 9.9439 \\
3 & 3.8614 & 4.6557 & 7.0346 & 7.8248 & 9.3290 \\
1 & 3.7464 & 4.5724 & 7.0075 & 7.8248 & 9.2013 \\
0.5 & 3.5695 & 4.4983 & 6.9776 & 7.8248 & 9.0429 \\
0 & 3.4604 & 4.4692 & 6.9631 & 7.8248 & 9.0501 & FEM \\
\hline 0 & 3.2662 & 4.4332 & 6.9410 & 7.8247 & 7.8306 & \\
\hline
\end{tabular}


TABLE 6: Effect of $R_{m}$ on the first five non dimensional frequency coefficients of a C-C beam system, with an elastic joint at $l_{2} \rightarrow 0, l_{3}=l_{1}$ (exact analytical solution).

\begin{tabular}{lccccc}
\hline$R_{m}$ & $\lambda_{1}$ & $\lambda_{2}$ & $\lambda_{3}$ & $\lambda_{4}$ & $\lambda_{5}$ \\
\hline$\rightarrow \infty$ & 3.9229 & 4.7227 & 7.0528 & 7.8284 & 7.8248 \\
\hline 500 & 3.9229 & 4.7227 & 7.0528 & 7.7679 & 10.1595 \\
100 & 3.9127 & 4.6887 & 7.0340 & 7.7352 & 10.1255 \\
50 & 3.9127 & 4.6676 & 7.0340 & 7.6520 & 10.1255 \\
20 & 3.9127 & 4.6104 & 7.0339 & 7.5490 & 10.1253 \\
10 & 3.9127 & 4.5322 & 7.0336 & 7.3245 & 10.1248 \\
3 & 3.9125 & 4.3200 & 7.0327 & 7.1710 & 10.1232 \\
1 & 3.9122 & 4.1216 & 7.0304 & 7.1188 & 10.1193 \\
0.5 & 3.9117 & 4.0365 & 7.0277 & 7.0664 & 10.1157 \\
0 & 3.9038 & 3.9296 & 7.0161 & \\
\hline
\end{tabular}

TABLE 7: Effect of $R_{m}$ on the first five non dimensional frequency coefficients of a SS-C beam system, with an elastic joint at $l_{2}=0.5 l_{1}$, beambeam connection (exact analytical solution).

\begin{tabular}{|c|c|c|c|c|c|}
\hline$R_{m}$ & $\lambda_{1}$ & $\lambda_{2}$ & $\lambda_{3}$ & $\lambda_{4}$ & $\lambda_{5}$ \\
\hline$\rightarrow \infty$ & 3.3920 & 4.4566 & 6.5383 & 7.5702 & 9.6637 \\
\hline 500 & 3.3920 & 4.4566 & 6.5383 & 7.5702 & 9.6637 \\
\hline 100 & 3.3903 & 4.4470 & 6.5374 & 7.5692 & 9.6607 \\
\hline 50 & 3.3883 & 4.4349 & 6.5354 & 7.5687 & 9.6541 \\
\hline 20 & 3.3821 & 4.4009 & 6.5297 & 7.5672 & 9.6337 \\
\hline 10 & 3.3723 & 4.3514 & 6.5216 & 7.5651 & 9.5984 \\
\hline 3 & 3.3318 & 4.1975 & 6.4976 & 7.5585 & 9.4430 \\
\hline 1 & 3.2548 & 4.0264 & 6.4721 & 7.5509 & 9.2192 \\
\hline 0.5 & 3.1959 & 3.9477 & 6.4602 & 7.5470 & 9.1105 \\
\hline 0 & 3.0686 & 3.8450 & 6.4432 & 7.5412 & 8.9626 \\
\hline
\end{tabular}

TABLE 8: Effect of $R_{m}$ on the first five non dimensional frequency coefficients of a SS-C beam system, with an elastic joint at $l_{2} \rightarrow 0, l_{3}=l_{1}$ (exact analytical solution).

\begin{tabular}{lccccc}
\hline$R_{m}$ & $\lambda_{1}$ & $\lambda_{2}$ & $\lambda_{3}$ & $\lambda_{4}$ & $\lambda_{5}$ \\
\hline$\rightarrow \infty$ & 3.3920 & 4.4566 & 6.5383 & 7.5702 & 7.5702 \\
\hline 500 & 3.3920 & 4.4566 & 6.5383 & 7.5314 & 9.6637 \\
100 & 3.3884 & 4.4394 & 6.5314 & 7.5123 & 9.6550 \\
50 & 3.3851 & 4.4237 & 6.5248 & 7.4501 & 9.6455 \\
20 & 3.3757 & 4.3812 & 6.5066 & 7.3751 & 9.6202 \\
10 & 3.3614 & 4.3234 & 6.4808 & 7.2219 & 9.5866 \\
3 & 3.3107 & 4.1713 & 6.4076 & 6.5068 \\
1 & 3.2413 & 4.0410 & 6.3398 & 7.383 & 9.4485 \\
0.5 & 3.2026 & 3.9903 & 6.3120 & 9.0983 & 9.4277 \\
0 & 3.1408 & 3.9290 & 6.2768 & 9.0654 & 9033 \\
\hline
\end{tabular}

be seen that the first, the third, and the fifth frequency coefficients remain practically constant and the second coefficients decrease by $20 \%$ and the fourth decrease by $11 \%$.

Table 7 presents the frequency coefficients of a simply supported-clamped structure with an elastic joint at $l_{2}=$ $0.5 l_{1}$.

In the present conditions, the first, the second, and the fifth frequency coefficients decrease in value and the third and fourth remain practically constant.

Table 8 contains the frequency coefficients of a simply supported-clamped beam system with an elastic connection at $\mathrm{P}, l_{2} \rightarrow 0, l_{3}=l_{1}$. It can be seen that all the frequency coefficients decrease in value between $8 \%\left(\lambda_{1}\right)$ and $3 \%\left(\lambda_{5}\right)$.
Figures 10 and 11 show graphically the variation of first three natural frequency coefficients for various locations of the elastic hinge: $l_{2} / l \rightarrow 0$ to $l_{2} / l \rightarrow 1$, with different combinations of $R_{z}, T_{w}, T_{u}$ and $R_{m}$. In both figures, it is clear that for the fundamental frequency coefficient the differences in the values of frequencies are not so significant.

\section{Conclusions}

The model presented in this paper allows studying the effect of the variation in the rigidity of the elastic supports and the elastic joint on the dynamical behavior of the beam system structure. The model enables an efficient, simple, and 


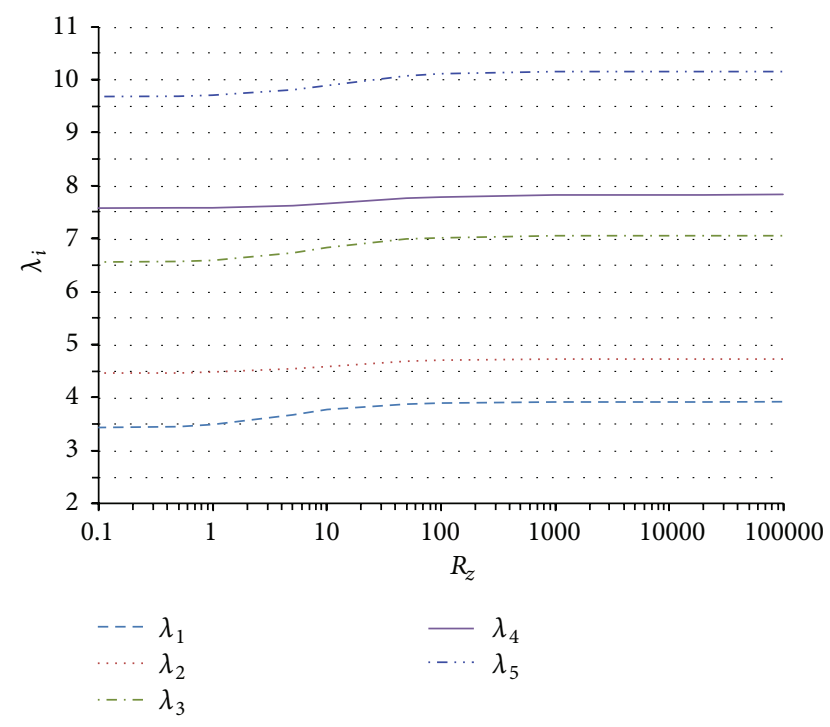

FIGURE 9: Effect of $R_{z}$ on the first five natural frequency coefficients. $l_{2}=l_{3}, v_{l_{1}}=v_{l_{2}}=0.5, v_{E I_{(2)}}=v_{E I_{(3)}}=1, v_{\rho A_{(2)}}=v_{\rho A_{(3)}}=1$, $R_{m} \rightarrow \infty, T_{w} \rightarrow \infty$, and $T_{u} \rightarrow \infty$.

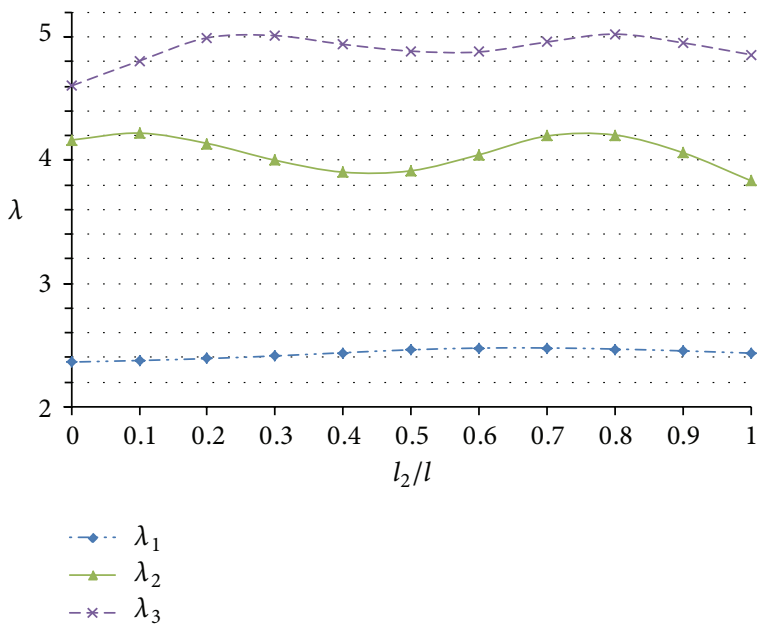

FIGURE 10: Variation of first three natural frequency coefficients with location of the elastic hinge, $l_{1}=l_{2}+l_{3}=l, l_{2} / l \in(0,1), v_{E I_{(2)}}=$ $v_{E I_{(3)}}=v_{\rho A_{(2)}}=v_{\rho A_{(3)}}=1, R_{z}=3, T_{w}=10, T_{u}=5$, and $R_{m}=2$.

straightforward way of computing natural frequency coefficients for L-Shaped-Structures with many different boundary conditions at simply supported, clamped, free, and elastically restrained. It was observed that the loss of rigidity of the translational springs significantly changes the natural frequency coefficients, especially the fundamental frequency coefficient. The presence of an elastic joint, modeling a beambeam connection, also implies changes in the natural frequencies when the rigidity is lost.

Although the model with elastic connection and supports does not represent the inherent complexities of real systems such as nonlinearity or damping, it provides conceptual insights regarding the fact that the loss of rigidity can cause significant changes in the dynamic behavior of the structure.

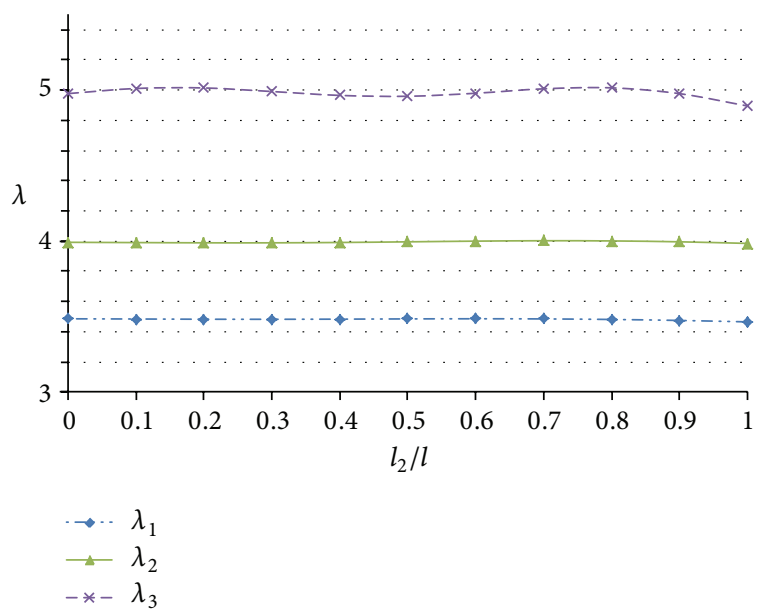

FIGURE 11: Variation of first three natural frequency coefficients with location of the elastic hinge, $l_{1}=l_{2}+l_{3}=l, l_{2} / l \in(0,1), v_{E I_{(2)}}=$ $v_{E I_{(3)}}=v_{\rho A_{(2)}}=v_{\rho A_{(3)}}=1, R_{z}=50, T_{w}=100, T_{u}=100$, and $R_{m}=20$.

In this sense, this model can be seen as a useful first approach to study the real system. The proposed analytical solution may be applied to include more complicating effects, such as elastic constraints at both ends, more than one internal elastic hinge, and another geometry with $\alpha_{1}+\alpha_{3} \neq \pi / 2$. Finally, it has been demonstrated that an elastic approach constitutes a reliable tool to deal with beam system structures.

\section{Acknowledgments}

The present work has been sponsored by Secretaría General de Ciencia y Tecnología of Universidad Nacional del Sur at the Department of Engineering and by Consejo Nacional de Investigaciones Científicas y Técnicas. The authors are indebted to the Chief of Mechanical Vibration Laboratory at the Department of Engineering, Ing. Santiago Maiz for his cooperation and useful suggestions, and to Mr. Gabriel Leguizamón for his careful preparation of the experimental device.

\section{References}

[1] P. A. A. Laura, B. H. Valerga de Greco, and C. P. Filipich, "Inplane vibrations of frames carrying concentrated masses," Journal of Sound and Vibration, vol. 117, no. 3, pp. 447-458, 1987.

[2] G. B. Warburton, The Dynamical Behaviour of Structures, Pergamon Press, Oxford, UK, 2nd edition, 1976.

[3] R. Blevins, Formulas for Natural Frequency and Mode Shape, Krieger Publishing, Malabar, Fla, USA, 2001.

[4] R. W. Clough and J. Penzien, Dynamics of Structures, Computers and Structures, Inc., Berkeley, Calif, USA, 3rd edition, 2004.

[5] S. Timoshenko and D. H. Young, Vibration Problems in Engineering, John Wiley \& Sons, New York, NY, USA, 5th edition, 1990.

[6] C. Mei, "Wave control of vibrations in multi-story planar frame structures based on classical vibration theories," Journal of Sound and Vibration, vol. 330, no. 23, pp. 5530-5544, 2011. 
[7] H. P. Lin and J. Ro, "Vibration analysis of planar serial-frame structures," Journal of Sound and Vibration, vol. 262, no. 5, pp. 1113-1131, 2003.

[8] J.-J. Wu, "Use of the elastic-and-rigid-combined beam element for dynamic analysis of a two-dimensional frame with arbitrarily distributed rigid beam segments," Applied Mathematical Modelling, vol. 35, no. 3, pp. 1240-1251, 2011.

[9] C. P. Filipich and P. A. A. Laura, "In-plane vibrations of portal frames with end supports elastically restrained against rotation and translation," Journal of Sound and Vibration, vol. 117, no. 3 , pp. 467-473, 1987.

[10] H. Bang, "Analytical solution for dynamic of a flexible L-shaped structure," Journal of Dynamic, vol. 19, no. 1, pp. 248-250, 1996.

[11] M. Gürgöze, "Comment on Analytical solution for dynamic analysis of flexible L-shaped structure," Journal of Guidance, Control and Dynamics, vol. 21, no. 2, p. 359, 1998.

[12] D. C. D. Oguamanam, J. S. Hansen, and G. R. Heppler, "Vibration of arbitrarily oriented two-member open frames with tip mass," Journal of Sound and Vibration, vol. 209, no. 4, pp. 651668, 1998.

[13] G. R. Heppler, D. C. D. Oguamanam, and J. S. Hansen, "Vibration of a two-member open frame," Journal of Sound and Vibration, vol. 263, no. 2, pp. 299-317, 2003.

[14] C. M. Albarracín and R. O. Grossi, "Vibrations of elastically restrained frames," Journal of Sound and Vibration, vol. 285, no. 1-2, pp. 467-476, 2005.

[15] H. P. Lee and T. Y. Ng, "In-plane vibration of planar frame structures," Journal of Sound and Vibration, vol. 172, no. 3, pp. 420427, 1994.

[16] R. O. Grossi and M. V. Quintana, “The transition conditions in the dynamics of elastically restrained beams," Journal of Sound and Vibration, vol. 316, no. 1-5, pp. 274-297, 2008.

[17] C. Y. Wang and C. M. Wang, "Vibrations of a beam with an internal hinge," International Journal Structural Stability Dynamic, vol. 1, pp. 163-167, 2001.

[18] Y. Y. Lee, C. M. Wang, and S. Kitipornchai, "Vibration of Timoshenko beams with internal hinge," Journal of Engineering Mechanics, vol. 129, no. 3, pp. 293-301, 2003.

[19] T.-P. Chang, G.-L. Lin, and E. Chang, "Vibration analysis of a beam with an internal hinge subjected to a random moving oscillator," International Journal of Solids and Structures, vol. 43, no. 21, pp. 6398-6412, 2006.

[20] M. V. Quintana, J. L. Raffo, and R. O. Grossi, "Eigenfrequencies of generally restrained Timoshenko beam with an internal hinge," Mecánica Computacional, vol. 29, pp. 2499-2516, 2010.

[21] R. A. Ratazzi, R. O. Grossi, and D. V. Bambill, "Vibraciones de una estructura aporticada con una rótula intermedia elásticamente restringida contra rotación y traslación," Mecánica Computacional, vol. 30, pp. 2499-2516, 2011.

[22] R. A. Ratazzi, D. V. Bambill, and C. A. Rossit, "Vibraciones en porticos con conexiones intermedias elasticas," Mecánica Computacional, vol. 31, pp. 2511-2627, 2012.

[23] H. Gorgun, "Geometrically nonlinear analysis of plane frames composed of flexibly connected members," Structural Engineering and Mechanics, vol. 45, no. 3, pp. 273-305, 2013.

[24] C. L. O. Santana and N. T. Mascia, "Wooden framed structures with semi-rigid connections: quantitative approach focused on design needs," Structural Engineering and Mechanics, vol. 31, no. 3, pp. 315-331, 2009.

[25] A. Reyes-Salazar, M. E. Soto-Lópeza, E. Bojórquez-Morab, and A. López-Barrazab, "Effect of modeling assumptions on the seismic behavior of steel buildings with perimeter moment frames," Structural Engineering and Mechanics, vol. 41, no. 2, pp. 183-204, 2012.

[26] Wolfram MATHEMATICA 9 software, Version 9, Copyright 1988-2012.

[27] ALGOR software, Version 23, 01, 2009.

[28] C. A. Morales, "Dynamic analysis of an L-shaped structure by Rayleigh-Ritz substructure synthesis method," Meccanica, vol. 44, no. 3, pp. 339-343, 2009. 

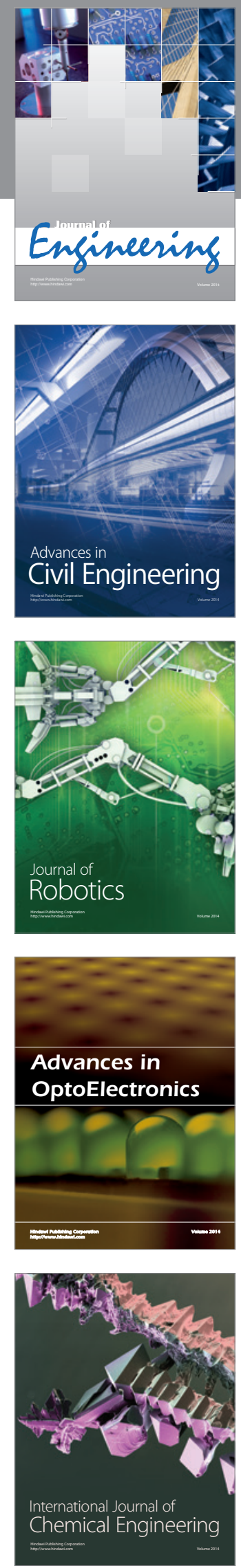

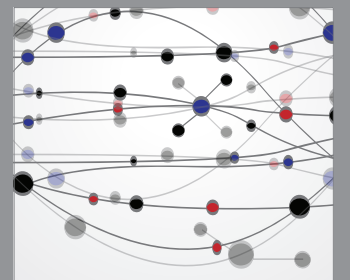

The Scientific World Journal
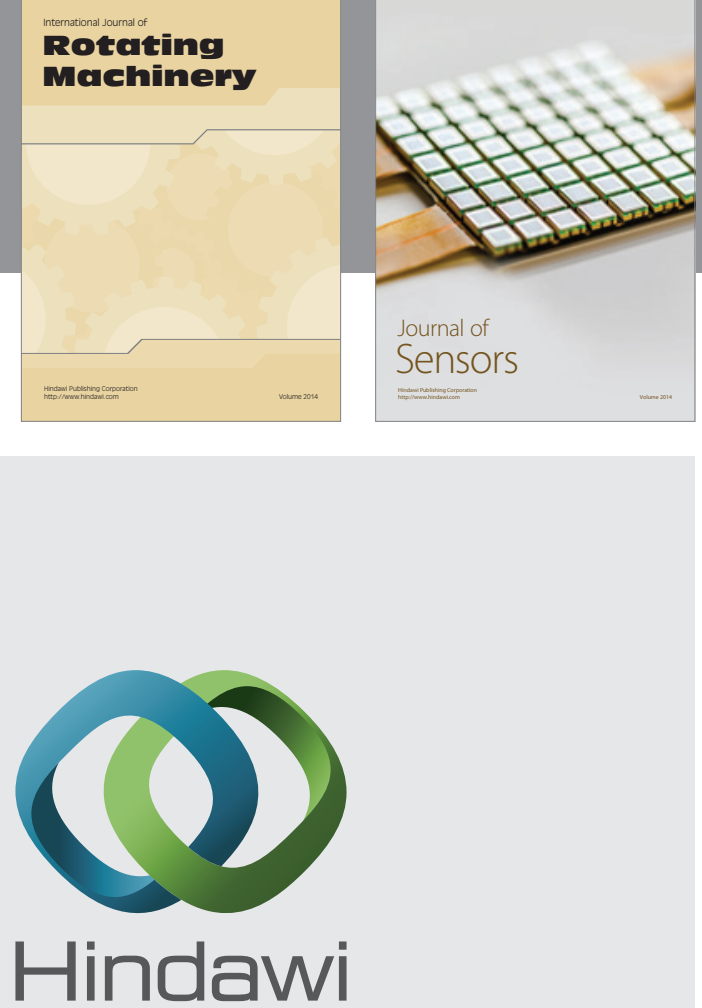

Submit your manuscripts at http://www.hindawi.com
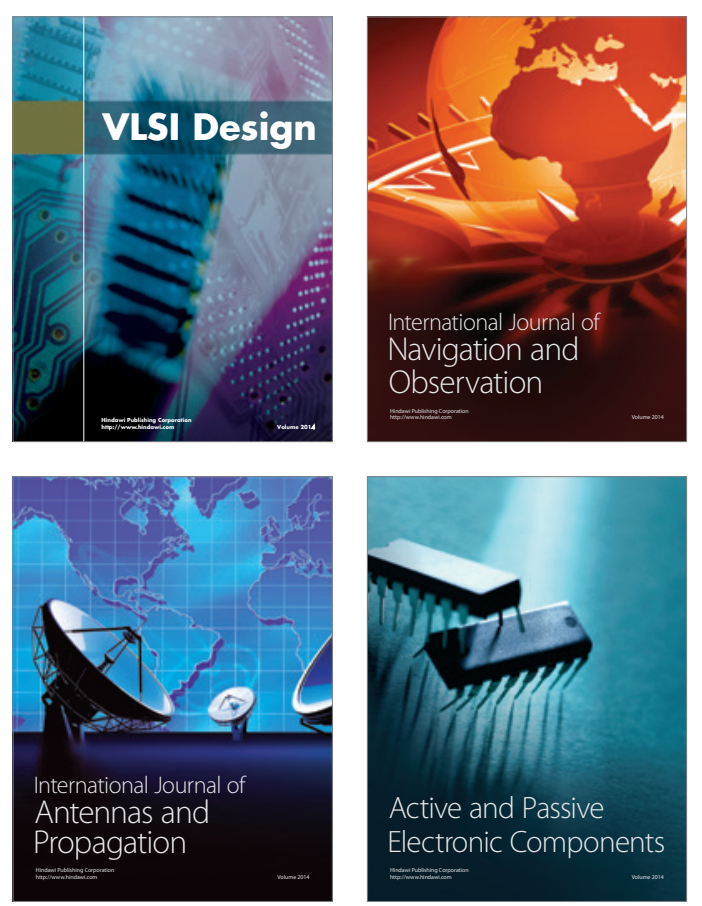
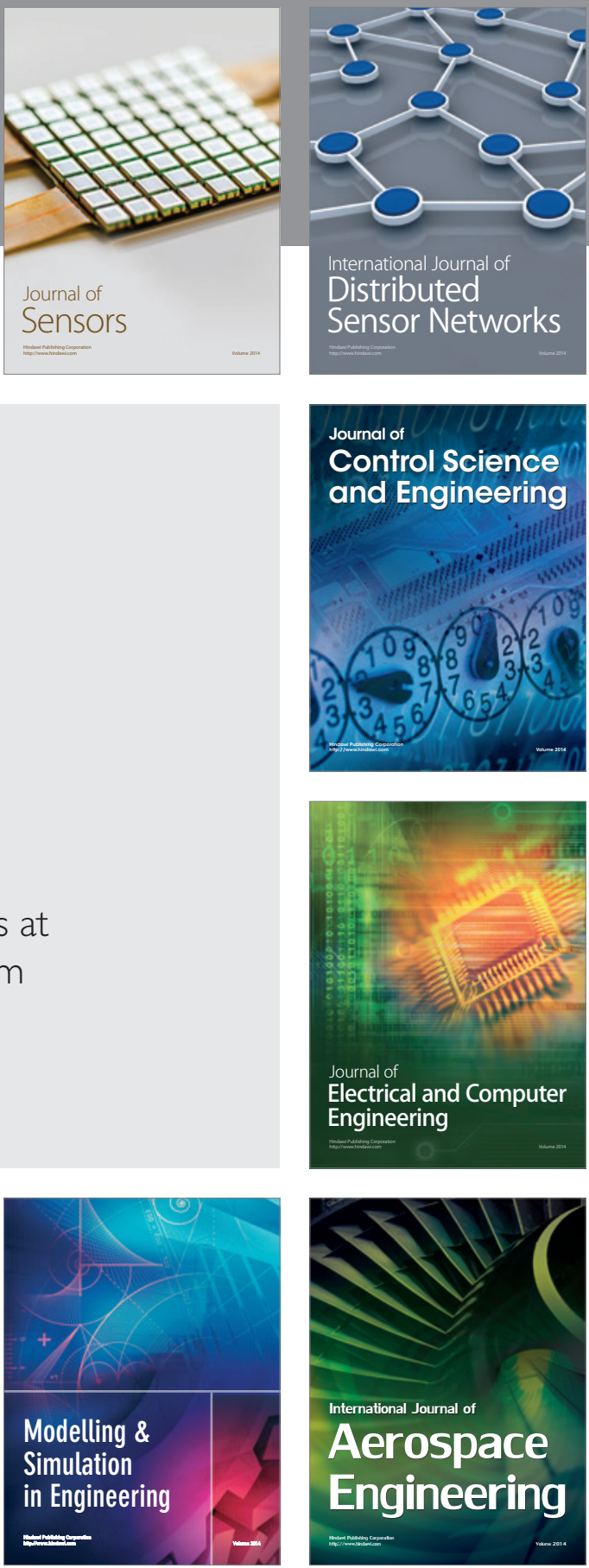

Journal of

Control Science

and Engineering
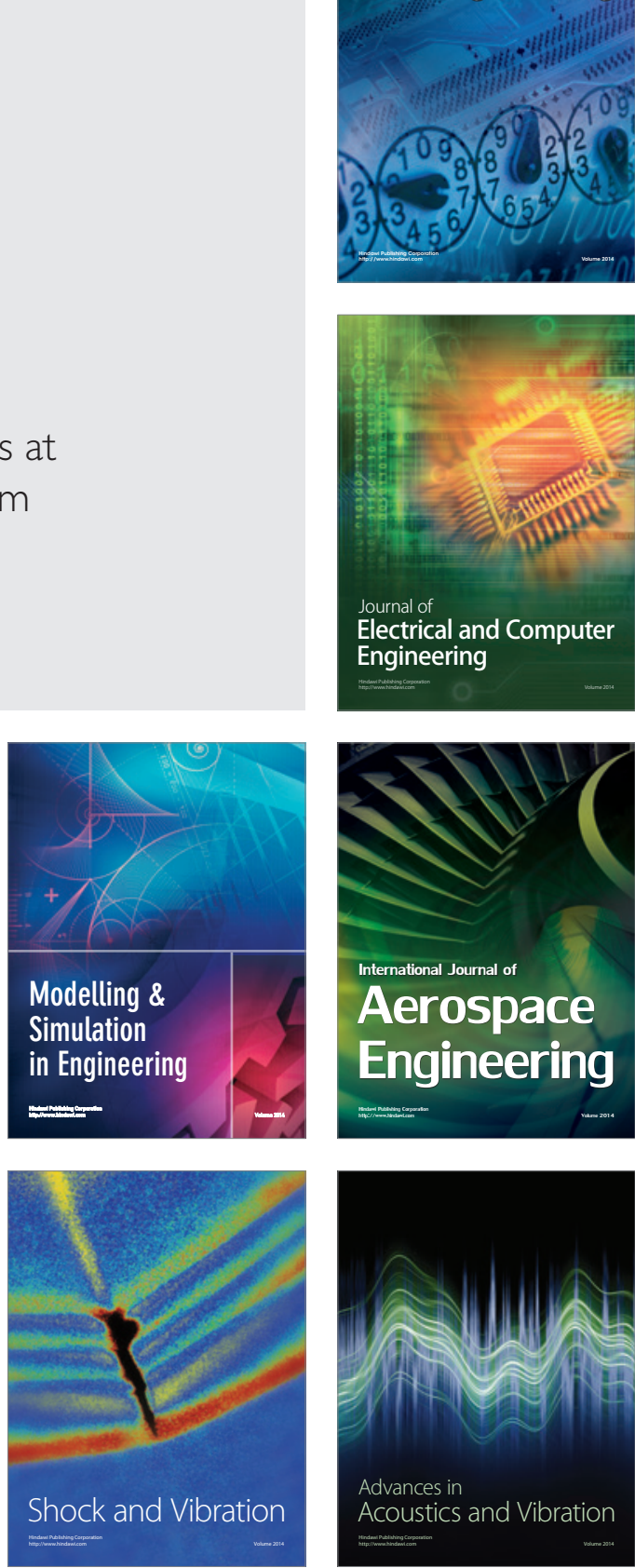